\title{
AVALIAÇÃO DE ACTIVOS IMOBILIÁRIOS
}

\author{
Joaquim Montezuma de Carvalho*
}

\section{INTRODUÇÃO}

Neste trabalho iremos caracterizar, sumariamente, o mercado imobiliário e abordar as principais metodologias de avaliação de activos imobiliários.

Apesar do investimento imobiliário representar uma parcela muito significativa do investimento global de um país, tem sido, comparativamente com o investimento em activos financeiros, muito pouco estudado. A título exemplificativo, e para os Estados Unidos da América, o valor total do mercado imobiliário, em meados dos anos 80 , foi de 4.5 triliões de dólares, enquanto que $o$ mercado accionista e obrigacionista rondou, no seu conjunto, 3.5 triliões de dólares.

Em termos genéricos, existem três metodologias para a avaliação quer dos activos reais quer dos activos financeiros. A primeira, a metodologia do valor actual dos cash-flows, relaciona o valor do activo com os respectivos cash-flows futuros. A segunda, a metodologia relacional, estima o valor do activo olhando para o preço de activos comparáveis. A terceira, a metodologia das opções considera o imóvel como uma contigent claim. Neste trabalho abordaremos, também, o método do custo, correntemente utilizado pelos avaliadores imobiliários, nos imóveis pouco transaccionados.

* Instituto Universitário de Desenvolvimento e Promoção Social - Pólo de Viseu da Universidade Católica Portuguesa. 


\section{ACTIVOS REAIS' $V E R S U S$ ACTIVOS FINANCEIROS ${ }^{2}$}

Existem várias características em comum entre os activos reais e os activos financeiros: o valor de ambos é determinado pelos seus cash-flows futuros, pela incerteza a eles associada e pelo seu crescimento esperado. Ceteris paribus, quanto maior o volume e crescimento dos cash-flows e menor o risco a eles associado, maior o valor do activo.

O mercado imobiliário apresenta algumas características específicas, que o diferenciam do mercado de capitais, a saber:

Reduzida liquidez resultante da morosidade e do escasso número de transações no mercado imobiliário. A transação de um imóvel implica normalmente negociações e trâmites legais muito demorados. Pode demorar um longo período de tempo para se conseguir obter o preço desejado para uma propriedade imobiliária e, mesmo assim, haverá sempre alguma incerteza quanto à concretização da transacção até ao momento da sua ultimação.

Natureza dos cash-flows gerados. Os activos imobiliários têm geralmente tempos de vida finitos (excluímos aqui os terrenos), em oposição às acções que apresentam tempos de vida infinitos. Os valores das acções tendem a aumentar com o tempo, enquanto que para um activo imobiliário o seu valor terminal pode ser menor que o seu valor inicial, devido à deterioração física do edifício, à obsolescência funcional e estrutural e à depreciação económica.

\subsection{Os activos imobiliários em carteiras de investimento}

Os estudos realizados nos Estado Unidos da América têm evidenciado a existência de reduzidas correlações entre as rentabilidades dos activos imobiliários e as dos activos mobiliários. Assim sendo, e recordando Harry Markowits, será possível diversificar o risco da carteira de investimento mobiliária incorporando nela activos imobiliários. Apesar do comportamento favorável das rentabilidades dos activos imobiliários, não se lhes tem dado muita atenção entre nós, como se pode constatar pelo aparecimento tardio, apenas no ano de 1987, dos Fundos de Investimento Imobiliário em Portugal.

Comparando o mercado imobiliário com o mercado de capitais dos Estados Unidos da América até ao ano de 1986 (tabela 2.1), é possível concluir que a "performance" do rácio retorno/risco para estes activos tem sido superior à "performance" do mesmo rácio para as acções e as obrigações. 
Tabela 2.1

RETORNOS MÉDIOS E VOLATILIDADES

\begin{tabular}{|l|c|c|c|c|}
\hline Índice & Retorno médio & Desvio padrão & Retorno/Desvio padrão & Início da série \\
\hline FRC & 13.87 & 4.37 & 3.17 & Jun. 1978 \\
REIT & 22.26 & 19.71 & 1.13 & Mar. 1974 \\
S\&P 500 & 9.71 & 15.35 & 0.63 & Mar. 1969 \\
Obrigaçöes \\
Tesouro Americano \\
$\begin{array}{l}\text { Bilhetes do Tesouro } \\
\quad \text { Americano }\end{array}$ & 7.91 & 11.50 & 0.69 & Mar. 1969 \\
& 7.51 & 0.82 & 9.16 & Mar. 1969 \\
\hline
\end{tabular}

Fonte: Zisler et al.

Analisando as correlações entre os três índices imobiliários FRC e EAFPI (ver apêndice e tabela 2.2), verificamos que estes estão correlacionados positivamente entre si e negativamente com os índices accionista e obrigacionista, o que vem ao encontro dos estudos acima mencionados. Infelizmente, e até ao momento, não foi realizado para a realidade portuguesa, um estudo sobre o comportamento das rentabilidades dos activos imobiliários relativamente às dos activos mobiliários. Para tal estudo, seria necessário antes de mais criar um índice imobiliário credível, que permitisse quantificar as suas correlações com os índices bolsistas existentes, BVLGERAL, BVL30, entre outros.

Tabela 2.2

MATRIZ DE CORRELAÇÃO

\begin{tabular}{|l|c|c|c|c|c|}
\hline ÍNDICES & FRC & EAFPI & S\&P 500 & $\begin{array}{c}\text { Obrigações } \\
\text { (US) }\end{array}$ & $\begin{array}{c}\text { Bilhetes do Tesouro } \\
\text { (US) }\end{array}$ \\
\hline FRC & 1.00 & 0.71 & -0.26 & -0.38 & 0.30 \\
EAFPI & 0.71 & 1.00 & -0.28 & -0.10 & 0.54 \\
S\&P 500 & -0.26 & -0.28 & 1.00 & 0.49 & -0.43 \\
$\begin{array}{l}\text { Obrigaçōes } \\
\text { (US) }\end{array}$ & -0.38 & -0.10 & 0.49 & 1.00 & -0.09 \\
$\begin{array}{l}\text { Bilhetes do Tesouro } \\
\text { (US) }\end{array}$ & 0.30 & 0.54 & -0.43 & -0.09 & 1.00 \\
\hline
\end{tabular}




\section{CARACTERIZAÇÃO DO MERCADO IMOBILIÁRIO}

Os activos imobiliários são extremamente heterogéneos, não existindo dois activos imobiliários totalmente iguais, havendo sempre algum factor diferenciador, como, por exemplo, a localização, a qualidade de construção, a orientação, etc.

Ao contrário daquilo que se passa no mercado de capitais, é extremamente difícil definir uma cotação uniforme para os activos imobiliários devido não só ao reduzido número de transacções de compra e venda destes bens, como à não existência de um local próprio para a sua realização, aquilo que poderíamos designar como "bolsa de imóveis". A impossibilidade de concentrar toda a oferta e procura, numa "bolsa de imóveis", dificulta a canalização de poupança para o investimento imobiliário, a transferência do risco de investimento, o incremento de liquidez e a revelação do preço.

A imperfeição ${ }^{3}$ deste mercado é ditada: $a$ ) pelas consideráveis assimetrias de informação observadas entre os investidores institucionais e os investidores individuais, que, na maioria dos casos, intervêm no mercado, uma ou duas vezes, ao longo de toda a sua vida; $b$ ) pelo reduzido número de vendedores e compradores intervenientes, capazes de influenciar o preço dos bens imobiliários; $c$ ) pelos elevados custos de transacção dos imóveis, comparativamente aos praticados no mercado de capitais. Em cada transacção imobiliária temos de considerar as despesas resultantes do imposto de sisa, do registo, da escritura, da avaliação, etc.

Em oposição ao mercado mobiliário, onde a formação das cotações é totalmente independente da proveniência geográfica dos títulos, no mercado imobiliário os activos estão dependentes do mercado da oferta e da procura locais. Em Portugal esta característica é ampliada devido ao enorme peso dos investidores individuais relativamente aos investidores institucionais.

Outra das singularidades destes activos resulta de, neste mercado, se transaccionar, para além da posse do bem, os direitos (de propriedade, de superfície, de usufruto, etc.) e as obrigações da sua utilização (imposto autárquico, condomínio, manutenção, etc.).

Por último, é de referir a indissociabilidade dos activos imobiliários ao terreno que the serve de suporte, sendo por isso difícil a separação económica entre o imóvel (apartamento, instalação industrial, armazém, etc.) do solo que o suporta, ou seja, a separação entre o capital-terra e o capital-benfeitorias. 


\section{MÉTODOS DE AVALIAÇÃO}

\subsection{Método do custo}

A ideia subjacente a este método é a de que um comprador informado não paga por um edifício um valor superior àquele que resultaria se tivesse comprado o terreno e construído o edifício.

No caso de estarmos a avaliar uma edificação nova, a metodologia consiste em adicionar, ao custo do terreno, os custos totais de construção, nomeadamente os custos directos de construção, os custos indirectos (licenças, projectos, fiscalização, taxas de imposto, etc.), os custos de comercialização, os custos de financiamento do capital próprio e do capital alheio.

No caso do objecto da nossa avaliação se tratar de um edifício antigo, teremos de subtrair ao custo da construção e do terreno os custos correspondentes à deterioração física (reparável e não reparável), à obsolescência funcional e estrutural (desactualização do layout, existência de novas tecnologias que permitam reduções dos custos operacionais), à depreciação económica (influências externas negativas, tais como a poluição sonora, atmosférica, etc.). Deveremos aqui alertar para a dificuldade em quantificar objectivamente estas depreciações, estando a sua determinação muito dependentes da experiência e do "feeling" do avaliador.

O método do custo (método do valor residual) também pode ser aplicado na avaliação de terrenos com potencialidade construtiva, quer urbanos quer por lotear. Neste caso vamos subtrair ao valor de mercado da propriedade, após as melhorias, o custo resultante dessas mesmas melhorias.

Figueiredo e Bezelga (1996:223) consideram que o método do custo deverá ser utilizado nas seguintes situações:

i) avaliação de propriedades cujo volume de transacções seja muito reduzido ou mesmo inexistente e cuja finalidade não seja a de obtenção de lucro (edifícios hospitalares, governamentais, museus, etc.);

ii) edifícios muito antigos;

iii) avaliações fiscais ou no âmbito da actividade seguradora.

\subsection{Método dos comparáveis ou dos múltiplos}

Da mesma forma que os múltiplos "pricelearnings" e o "price/book" são utilizados na avaliação de acções, é possível empregar múltiplos como o preço por metro quadrado ou a taxa de capitalização na avaliação de imóveis.

O método dos comparáveis, ou dos múltiplos, consiste na multiplicação de uma grandeza ligada à exploração ou à situação patrimonial do imóvel por um coeficiente correspondente a um rácio encontrado no mercado imobiliário, para outros imóveis com características semelhantes, e que relaciona o valor de mercado desses activos com a mesma grandeza do imóvel a avaliar. A ideia que suporta este método é a de que um investidor informado não está disposto a pagar 
por uma propriedade um valor superior à aquele que foi pago, recentemente, por propriedades comparáveis.

A aplicação destes métodos só é possível quando exista disponível um número suficiente de dados de transacções de propriedades análogas. Situação que nem sempre ocorre.

As transacções imobiliárias consideradas análogas e comparáveis deverão corresponder sempre a operações de compra e venda julgadas normais para o mercado, isto é, onde o comprador e o vendedor detêm informação suficiente sobre os valores praticados no mercado e não exista coacção por uma das partes envolvidas na transacção.

O múltiplo de dimensão mais utilizado é o do preço por metro quadrado, determinado através do quociente do preço do imóvel pela sua área bruta. Uma vez que subsistem sempre algumas diferenças entre a propriedade a avaliar e as propriedades comparáveis, nomeadamente ao nível da localização, da idade, da qualidade de construção, etc., existe a necessidade de realizar ajustamentos recorrendo às técnicas de homogenização e da análise estatística. À semelhança do método de custo, este tem a vantagem de permitir avaliar activos imobiliários não geradores de rendimentos.

Os múltiplos de rendimento mais aplicados são os do rendimento bruto e o da taxa de capitalização. $O$ primeiro resulta da divisão do rendimento bruto anual (potencial ou efectivo) ${ }^{4}$ pelo preço da propriedade. $O$ segundo, a taxa de capitalização define-se como o quociente do resultado operacional pelo preço da propriedade ${ }^{5}$ e é utilizada na avaliação de imóveis geradores de rendas (ex. escritórios, lojas comerciais, etc.) ou de rendimentos provenientes das actividades nela desenvolvidas (ex. hóteis, parques de estacionamento, etc.). Note-se que os resultados operacionais precedem sempre os encargos financeiros, a fim de que não haja distorções resultantes da alavancagem financeira. A taxa de capitalização assim definida não corresponde à taxa de rendibilidade do investimento imobiliário, visto que a primeira não considera nem a taxa de crescimento do rendimento nem o valor do imóvel no final do período de posse.

Para a situação em que o resultado operacional e o valor do imóvel crescem a uma mesma taxa, teremos a seguinte relação entre a taxa de capitalização e a taxa de rendimento do investimento:

$$
\boldsymbol{R}=\boldsymbol{r}-\boldsymbol{g}
$$

onde,

$R:$ taxa de capitalização;

$r$ : taxa de rendibilidade do investimento;

94 g: taxa de crescimento do resultado operacional e do valor do imóvel. 
Podemos assim concluir que, se aplicarmos uma mesma taxa de capitalização a propriedades comparáveis, mas com diferentes potenciais de crescimento, quer em termos de resultados operacionais, quer em termos de mais valias, estamos a introduzir um erro grosseiro na nossa estimativa de avaliação. No entanto, e felizmente, ao contrário daquilo que sucede com a aplicação do método dos múltiplos a activos financeiros, onde é frequente acções do mesmo sector apresentarem diferentes taxas de risco e de crescimento, no mercado imobiliário, as propriedades da mesma classe e com a mesma localização apresentam usualmente taxas de crescimento e de risco análogas.

O valor estimado para o imóvel é extremamente sensível ao valor do múltiplo considerado; por conseguinte, a determinação do múltiplo deve ser cuidadosamente analisada e justificada.

Os dois multiplicadores de rendimento apresentam, relativamente aos múltiplos de dimensão, a vantagem de incorporar diferenças de escala, qualidade de construção, localização e idade, visto que estas diferenças afectam simultaneamente o rendimento e o preço do imóvel.

Os métodos baseados nos múltiplos apresentam a vantagem de serem de fácil compreensão e de simplicidade na sua aplicação, não implicando o domínio de conceitos técnicos e económicos muito complicados.

\subsection{Método dos cash-flows actualizados}

Figura 4.1

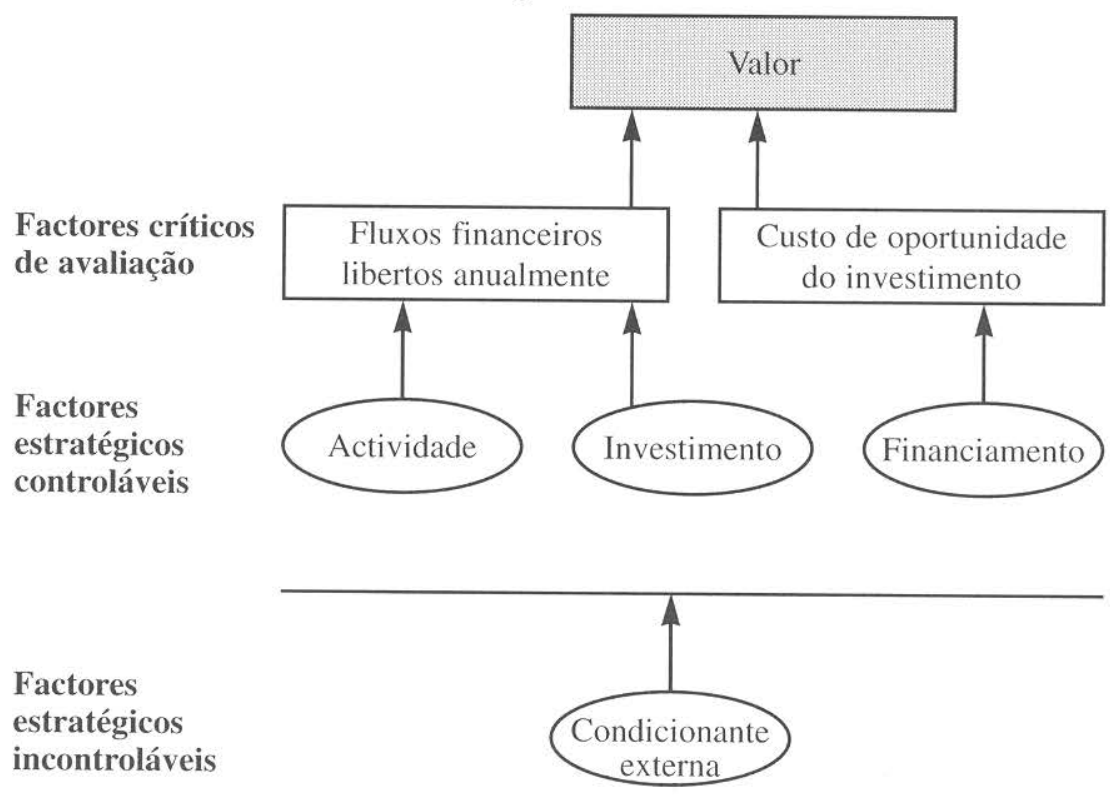


Ao contrário dos métodos baseados em múltiplos de rendimento, a metodologia dos cash-flows actualizados tem em linha de conta não só os resultados operacionais presentes mas também aqueles que se esperam obter no futuro, bem como a valorização do imóvel.

O método dos cash-flows actualizados pressupõe que o valor de um qualquer activo, real ou financeiro, corresponde ao somatório dos seus cash-flows futuros, descontados a uma taxa que incorpore o risco subjacente a aplicações alternativas semelhantes. É um método complexo que depende do estabelecimento de um vasto conjunto de pressupostos sobre o ambiente económico do investimento e das condições da sua exploração futura.

Na figura 4.1 apresentam-se os principais inputs que determinam os dois factores considerados críticos para este tipo de avaliação, nomeadamente os fluxos gerados e o custo de oportunidade para um investimento de risco semelhante, implícito na taxa de actualização.

O valor do activo resulta deste modo da capacidade deste gerar fundos, considerados em sentido lato, que serão distribuídos aos detentores do capital investido.

A determinação do valor do activo financeiro ou real, segundo esta perspectiva, corresponde ao somatório dos cash-flows futuros, descontados a uma taxa de actualização que tenha em conta o risco do investimento.

$$
V=\sum_{i=1}^{n} \frac{C F_{i}}{\left(1+r_{i}\right)^{i}}+\frac{V R}{\left(1+r_{n}\right)^{n}}-I
$$

onde,

V: valor do activo;

$\mathrm{CF}_{\mathrm{i}}$ : cash-flow de exploração no período i;

VR: valor residual no final do ano $\mathrm{n}$;

$r_{i}$ : taxa de actualização no período i $(i=1,2,3,4,5)$;

I: investimento realizado.

Os pressupostos subjacentes à construção dos cash-flows como base para a determinação do valor do activo imobiliário, de acordo com este método de avaliação, são os seguintes:

a) O valor actual dos cash-flows descontados representa o valor do activo para todos os financiadores (de capital próprio e de capital alheio);

b) O valor do activo é calculado a partir dos resultados operacionais (resultados económicos de exploração), devendo considerar-se o efeito fiscal que resulta da aplicação da taxa marginal de IRC aos resultados operacionais positivos, caso existam;

c) Ao valor obtido, tal como se ilustrou em b), são adicionados todos os custos que não representam saídas efectivas de fluxos monetários, tais como as amortizações e as provisões do exercício; 
d) São igualmente consideradas as variações no fundo de maneio que reflectem anualmente os montantes investidos em activos circulantes, líquidos dos respectivos passivos, incluindo-se o valor de caixa correspondente apenas ao disponível de exploração e excluindo-se os montantes existentes em empréstimos no curto prazo pelos motivos apontados em a);

e) Tendo por objectivo determinar a totalidade dos fluxos monetários gerados em cada período, ao somatório das rubricas consideradas nos alíneas anteriores, subtrai-se o total do investimento em imobilizado de exploração, bem como qualquer outro tipo de pagamentos (líquidos de eventuais recebimentos).

A taxa de actualização utilizada resulta da média ponderada pela estrutura de financiamento, entre a taxa média de custo do capital alheio e da taxa de custo dos capitais próprios, representando esta última o nível de rendimento requerido pelos investidores para um investimento de risco semelhante.

$$
r_{i}=\frac{S}{V} \times r_{e}+\frac{D}{V} \times r_{d} \times(1-t)
$$

onde,

$r_{i}$ : taxa de custo médio do capital;

$r_{\mathbf{e}}$ : taxa de custo dos capitais próprios;

$\mathbf{r}_{\mathbf{d}}$ : taxa de custo do capital alheio;

D: valor actual da dívida;

$\mathrm{S}$ : valor dos capitais próprios;

$\mathrm{V}$ : valor do activo $(\mathrm{V}=\mathrm{D}+\mathrm{S})$;

t: taxa de imposto sobre o rendimento

\subsubsection{Estimativa do custo do capital próprio}

\subsubsection{Modelo CAPM}

Os dois modelos mais utilizados para estimar o custo do capital próprio dos activos financeiros são o capital asset pricing model (CAPM) e o arbitrage pricing model (APT). Ambos os modelos consideram que o risco relevante de uma activo, financeiro ou real, é aquele que não é diversificável, ou seja, o risco sistemático.

No modelo CAPM a taxa de custo do capital próprio é composta por duas componentes: a taxa rentabilidade de um investimento sem risco e um prémio de risco que reflicta o risco do investimento.

A taxa de rentabilidade de uma aplicação sem risco será estimada, assumindo-se que a rentabilidade, obtida num investimento a longo prazo num activo sem 
risco, a taxa fixa (Obrigações do Tesouro) deverá ser igual à rentabilidade obtida em reinvestimentos sucessivos em aplicações de curto prazo.

O prémio de risco não reflectirá o risco total do título, mas sim o risco sistemático, ou seja, a sensibilidade da rentabilidade deste investimento em relação à rentabilidade global do mercado. Assim, este modelo assume implicitamente a possibilidade de diversificação completa das carteiras dos investidores, embora tal seja mais difícil para o caso de activos imobiliários, devido ao avultado número de imóveis necessários, resultante da fraca correlação existente entre os activos imobiliário, de acordo com Brown (citado em Figueiredo, R., Medição de Desempenho do Investimento no Imobiliário, 1996: 201), pelo que o valor encontrado para o prémio de risco deverá ser o valor máximo do intervalo valorativo.

Em termos analíticos, a taxa de custo de capital próprio deverá ser calculada recorrendo à seguinte metodologia:

$$
\begin{aligned}
& \mathbf{R}_{\mathrm{e}}=\mathbf{R}_{\mathrm{f}}+\boldsymbol{B}_{\mathrm{k}}\left(\mathbf{R}_{\mathrm{m}}-\mathbf{R}_{\mathrm{f}}\right) \\
& \boldsymbol{B}_{\mathrm{k}}=\boldsymbol{B}_{0}[\mathbf{1}+\mathrm{D} / \mathrm{S}(\mathbf{1 - t})]
\end{aligned}
$$

onde,

$\mathrm{R}_{\mathbf{e}}$ : taxa de rentabilidade exigida para os capitais próprios;

$\mathrm{R}_{\mathrm{r}}$ : taxa de retorno sem risco esperada;

$B_{\mathbf{k}}$ : beta do capital próprio;

$\mathrm{R}_{\mathrm{m}}$ : taxa de retorno médio do mercado;

$b_{0}$ : beta não alanvacado, beta do imóvel quando este é totalmente financiado com capital próprio;

D: valor actual da dívida;

S: valor dos capitais próprios.

Ao considerarmos que o risco do activo imobiliário pode ser dado pelo beta do CAPM, surgem alguns problemas. Enquanto que para um activo financeiro (ex. acção cotada em bolsa) existem disponíveis as cotações dos preços do activo e do índice de mercado para longos horizontes de tempo, para o activo imobiliário não é possível colher a mesma informação. Os activos imobiliários individuais são transaccionados com uma frequência reduzida, havendo necessidade de recorrer a índices representativos dos mesmos. Em Portugal, não existem ainda índices representativos das diferentes classes de activos imobiliários (residenciais, comerciais, industriais) e, mesmo nos países em que estes índices são publicados, persiste o problema da heterogeneidade (diferentes localizações, idades, áreas, qualidade de construção, etc.), dentro de cada classe imobiliária.

$O$ índice do mercado bolsista utilizado para calcular o beta de uma acção não representa satisfatoriamente o índice de mercado teórico, pois este deveria incluir 
todos os activos da economia na mesma proporção do seu valor de mercado. A utilização de um índice bolsista como índice de mercado resulta na marginalização da grande maioria dos investimentos imobiliários consubstanciados, cujo valor representa uma fracção importante da economia (ver gráfico a seguir).

\section{VALOR DE MERCADO DE DIFERENTES CLASSES DE ACTIVOS}
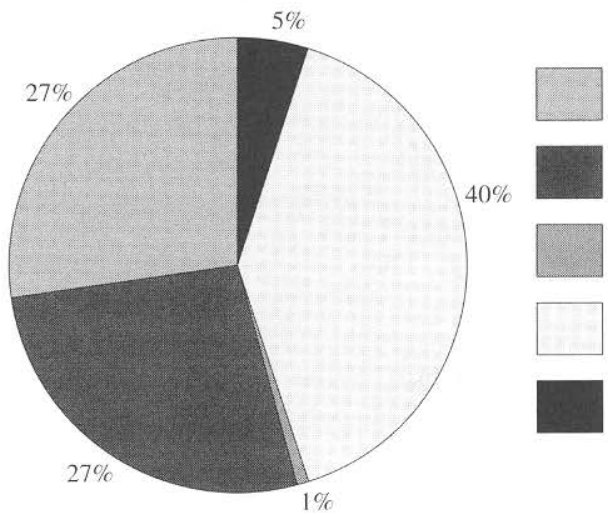
Imóveis USA

Acções disponíveis mundialmente

Metais preciosos

Obrigações disponíveis mundialmente

Dinheiro

Fonte: (Damodaran: 1996).

Existem, no entanto, algumas soluções de índole prática para a determinação da taxa de actualização:

- O emprego de fundos de investimento imobiliários é uma solução exequível para a determinação do beta. Utiliza-se um fundo que seja representativo da classe que pretendemos avaliar. Devemos salientar, no entanto, que nem sempre o fundo imobiliário se comporta da mesma forma que o investimento directo, constituindo no entanto uma aproximação plausível.

- Havendo um índice disponível para cada classe, o beta do modelo CAPM pode ser determinado através da regressão linear deste índice relativamente ao índice de mercado. Esta solução traz consigo alguns problemas, entre os quais se conta o facto destes serem construídos com base no seu valor venal, determinado de acordo com o valor presumível em condições normais de mercado no momento da avaliação e não em transacções reais, escamoteando alguma da volatilidade existente e, ainda, o facto dos retornos destes índices só estarem disponíveis para períodos de tempo relativamente longos, normalmente um ano ou um trimestre. 
A metodologia do CAPM considera a existência de um mercado perfeito, ignorando alguns dos riscos intrínsecos aos activos imobiliários, nomeadamente:

- Custos de informação. A informação no mercado imobiliário é mais dispendiosa e mais difícil de alcançar do que no mercado de capitais, sendo necessário adicionar à taxa de actualização obtida pelo método CAPM um prémio que contemple este risco de informação adicional.

- Reduzida liquidez. Tal como já foi referido neste trabalho, a falta de liquidez, resultante da morosidade e do diminuto número de transacções executadas, leva a que, ao valor actualizado obtido, se tenha de multiplicar um factor corrector da insuficiência de liquidez.

- Heterogeneidade do bem imobiliário, não existem dois imóveis completamente iguais, contanto que há sempre algum factor diferenciador (idade, qualidade de construção, orientação, etc).

\subsubsection{A realização de inquéritos como alternativa ao modelo CAPM.}

O modelo CAPM pressupõe a existência de uma carteira bem diversificada, custos de transação reduzidos e a liquidez dos activos. Ora, como já tivemos oportunidade de referir, os activos imobiliários estão longe de cumprir estes pressupostos, pelo que a realização de inquéritos a potenciais investidores, sobre qual a taxa de retorno, a exigir para cada bem imobiliário, surge como uma alternativa razoável para a estimativa do custo do capital próprio.

\section{Vantagens dos inquéritos:}

- Os inquéritos permitem estimar o retorno exigido pelo investimento imobiliário, tomando em consideração as especificidades da classe em geral (residencial, industrial, comercial) e os atributos do imóvel em particular (ex. localização, qualidade de construção).

- Os inquéritos não são baseados em modelos abstractos de risco e de retorno (CAPM) que ignoram na maioria das vezes os riscos específicos dos activos imobiliários, mas pelo contrário, fundamentam-se em investimentos concretos.

\section{Desvantagens dos inquéritos:}

- Esta metodologia aplica-se apenas quando no mercado existe um número de investidores reduzido e relativamente homogéneo.

- Como output do inquérito, temos uma série de taxas de retorno que traduzem as diferentes percepções de risco dos investidores participantes no inquérito. Na realidade, o que é pretendido é uma taxa única que traduza as 
percepções de risco dos investidores. É possível, no entanto, socorrermo-nos das técnicas estatísticas com o intuito de minorar esta desvantagem.

- Não especifica limites mínimo e máximo para as taxas estimadas. O modelo CAPM especifica, sempre, um valor mínimo para a taxa de retorno, ou seja, a taxa de retorno isenta de risco.

- O CAPM permite ao investidor assumir uma atitude proactiva (ex. rectificação do Beta alavancado resultante de uma nova estrutura de financiamento). $O$ inquérito pressupõe sempre uma atitude reactiva por parte do estimador do custo de capital próprio.

\subsubsection{Determinação do custo do capital alheio}

A taxa de custo médio do capital alheio será igual à taxa de juro média ponderada do passivo remunerado, conforme a seguinte fórmula:

onde,

$$
r_{d}=\sum \alpha_{i} \times B_{i}
$$

$r_{d}$ : taxa de custo médio do capital alheio;

$\alpha_{i}: \quad$ taxa de juro do iésimo empréstimo;

$\beta_{\mathrm{i}}: \quad$ montante do iésimo empréstimo.

\subsubsection{Estimativa dos Cash-flows}

Nem todos os activos imobiliários geram cash-flows. Para aqueles que satisfaçam esta condição, é necessário em primeiro lugar identificar os cash-inflows e os cash-outflows para o período explícito, ou seja, o período de tempo sobre o qual é possível realizar projecções credíveis.

\section{Cash-inflows}

Geralmente os cash-flows gerados por activos imobiliários tomam a forma de rendas. Para estimar essas rendas é necessário ter em consideração: o seu comportamento histórico (preços e taxas de ocupação); a oferta e a procura dos espaços de arrendamento; e as condições do ambiente económico (taxas de juro, nível de emprego, rendimento disponível). Da análise destes factores definem-se valores para as rendas futuras e para as taxas de ocupação.

\section{Cash-outflows}

A propriedade imobiliária acarreta despesas fixas e variáveis. Como principais despesas fixas, temos o imposto sobre a propriedade (imposto autárquico), os custos de manutenção do imóvel, custos do seguro, entre outros. Os custos variáveis são proporcionais à utilização do imóvel (ex. custos de electricidade, água). 
Através do método directo os cashflows de exploração, definido como a diferença entre as receitas de exploração e as despesas de exploração. No entanto, e para a maioria dos casos, esta informação não existe disponível, pelo que o avaliador terá de se socorrer do método indirecto (Oliveira Marques, 1996: 3)

$+\quad$ Resultados antes de Impostos e Encargos Financeiros

+ Amortizações e Reintegrações

+ Dotações para provisões (excepto provisão para impostos)

- Variação positiva dos créditos a curto prazo e existências

$+\quad$ Variação positiva das dívidas a curto prazo

- Imposto pagos

- Investimento de substituição

$=$ Cash-flows

A taxa de crescimento dos cash-inflows e dos cash-outflows é extremamente importante no processo de avaliação. Para condições de mercado estáveis, podemos considerar a taxa de crescimento coincidente com a taxa de inflação do período em causa.

Aos fluxos gerados de tesouraria actualizados para o período explícito é necessário adicionar um valor residual. Este valor residual pode ser estimado recorrendo a diferentes metodologias baseadas em pressupostos distintos, das quais destacamos as seguintes.

A primeira metodologia capitaliza o valor actual à taxa de inflação anual esperada para o período explícito, tendo-se:

$$
\text { Valor residual }=\text { Valor actual } \times(1+\operatorname{Inf})^{n}
$$

onde,

inf: taxa de inflação

$\mathrm{n}$ : número de anos do período explícito

Teremos então que o valor do imóvel será dado por:

$$
V=\sum_{i=1}^{n} \frac{C F_{i}}{\left(1+r_{i}\right)^{\mathrm{i}}}+\frac{V \times(1+\mathrm{inf})^{n}}{\left(1+r_{n}\right)^{n}}-\mathrm{I}_{(1)}
$$

Para obtermos o valor do imóvel existe a necessidade de resolver a expressão algébrica ( 1 ) em ordem a $\mathrm{V}$, donde vem que,

$$
V=\frac{\sum_{i=1}^{n} \frac{C F_{i}}{\left(1+r_{i}\right)^{i}}-I}{1-\frac{(1+\text { inf })^{n}}{\left(1+r_{n}\right)^{n}}}
$$


A Segunda metodologia considera que o cash-flow do último ano crescerá eternamente a uma taxa constante (modelo de Gordon):

valor residual: $\frac{\mathrm{CF}_{\mathrm{n}+1}}{\mathrm{r}-\mathrm{g}}$

onde,

$\mathrm{CF}_{\mathrm{n}+1}$ : cash-flow no período $\mathrm{n}+1$;

r: taxa de actualização;

g: taxa de crescimento constante.

O método do valor residual pressupõe que a propriedade tem uma duração infinita o que, como nós sabemos, não corresponde à realidade. Desta forma é lícito considerar antes que o cash-flow do último ano do período explícito crescerá a uma taxa constante até ao final da sua vida útil, donde virá a seguinte expressão:

valor residual $C F_{n+1} \times\left[\frac{1-\frac{(1+g)^{n}}{(1+r)^{n}}}{r-g}\right]$

com, n: número de anos de vida útil

\subsection{Método da regressão linear}

Neste método procuram estabelecer-se relações lineares entre os múltiplos aplicados no método dos comparáveis (ex. preço por metro quadrado) e os factores considerados relevantes na avaliação de um imóvel numa determinada localização, tais como as taxas de ocupação, a capacidade para gerar rendas, a qualidade de construção, entre outros.

\subsection{Método Binomial}

O método binomial foi desenvolvido por Cox, Ross e Rubinstein em 1979 para avaliação de opções e outros produtos derivados.

Este método pressupõe a não existência de oportunidades de arbitragem e a possibilidade de constituição de uma carteira, com opções e com o activo subjacente, cujo valor no final do período é totalmente certo. Como não há incerteza quanto ao retorno da carteira, ou seja não há risco, então o seu retorno e, para não haver arbitragem, deverá coincidir com o dos activos isentos de risco.

Se considerarmos que no momento presente $(t=0)$ o valor da opção é igual a $f$ e o valor do activo subjacente é igual a $S$ e que, no momento futuro $(t=T)$, o preço do activo pode subir para $\mathrm{Su}, \mathrm{com} u>1$, ou descer para $\mathrm{Sd}$, com $\mathrm{d}<1$, enquanto o 
preço da opção poderá tomar o valores $\mathrm{f}_{u}$ ou $\mathrm{f}_{\mathrm{d}}$, respectivamente, a nossa carteira consiste numa posição longa ${ }^{6} \mathrm{em} \Delta$ activos subjacentes e uma posição curta ${ }^{7} \mathrm{em}$ opções. A carteira é isenta de risco se o valor de $\Delta$ for determinado de forma a que o valor final da carteira seja independente do cenário ocorrido. Se ocorrer o cenário favorável, o valor da carteira será igual a,

$$
\mathrm{Su} \Delta-\mathrm{fu}
$$

Se acontecer o cenário desfavorável, o valor da carteira será igual a,

$$
\mathrm{Sd} \Delta-\mathrm{f}_{\mathrm{d}}
$$

E os valores da carteira serão iguais para ambos os cenários quando,

$$
S_{d} \Delta-f_{d}=\operatorname{Su} \Delta-f_{u}
$$

Resolvendo a expressão anterior em ordem a, $\Delta$ obtemos que,

$$
\Delta=\frac{F_{u}-f_{d}}{S(u-d)}
$$

Para determinar o valor da carteira no momento actual será necessário actualizar, à taxa isenta de risco rf, o valor da carteira no momento $\mathrm{T}$, donde vem,

$$
\left(S_{u} \Delta-f_{u}\right) \frac{1}{\left(1+r_{f}\right)^{T}}
$$

O custo inicial do carteira é igual a,

$$
S \Delta-f
$$

Igualando as duas últimas expressões temos que,

$$
S \Delta-f=\left(S_{u} \Delta-f_{u}\right) \frac{1}{\left(1+\mathrm{r}_{f}\right)^{r}}
$$

Desenvolvendo a expressão anterior em ordem a f obtemos a expressão que nos dá o valor da opção no momento $(\mathrm{t}=0)$,

$$
j=S \Delta-\left(S u \Delta-f_{u}\right) \frac{1}{\left(1+r_{f}\right)^{T}}
$$




\subsubsection{Aplicação do Método Binomial a Activos Imobiliários}

O método binomial pode ser aplicado, em situações de incerteza, no processo avaloatório de activos imobiliários. Sheridan Titman (1985: 505) aplicou este método à avaliação de terrenos urbanos em que existem incertezas relativamente ao tipo de edifício passível de ser construído e respectivos preços. A intuição por detrás deste modelo é a de que em muitos casos é melhor adiar o investimento, mantendo em aberto no futuro a opção de escolha do projecto que maximize o valor actualizado; por outras palavras, estamos a atribuir valor à flexibilidade. Este valor pode ser estimado recorrendo ao método binomial. Para o nosso caso concreto, o terreno livre representa uma opção de compra de diferentes tipos de edifícios (activo subjacente), a um preço de exercício igual ao respectivo custo de construção.

Para aplicar o modelo binomial na avaliação de um terreno urbano, vamos considerar os seguintes pressupostos: a posse do terreno livre não acarreta custos nem gera proveitos; só existe incerteza relativamente ao preço que cada apartamento terá no futuro e que o mercado é perfeito.

Consideremos o seguinte exemplo:

- a taxa de juro isenta de risco (r) é de $12 \%$

- O valor corrente do apartamento é de 100 u.m.

- O valor futuro do apartamento pode assumir os valores seguintes:

- 120 u.m. num cenário favorável

- 90 u.m. num cenário desfavorável

- Os custos de construção (neste ano e no próximo) são:

- 480 u.m. para um prédio de 6 apartamentos

- 810 u.m. para um prédio de 9 apartamentos

Existem, portanto, duas alternativas possíveis: construir o prédio hoje ou construir no próximo ano. Se construirmos hoje, e optarmos pelo prédio de seis apartamentos, temos um proveito de 600 u.m. (100 u.m./apartamento x 6 apartamentos) e um custo de 480 u.m., ou seja, um lucro de 120 u.m.. Se optarmos pelo prédio de 9 andares, temos um proveito de $900 \mathrm{u} . \mathrm{m}$. (100 u.m./apartamento x 9 apartamentos) e um custo de 810 u.m, ou seja, um lucro de 90 u.m. Donde vem que o valor do terreno será igual 120 u.m., correspondente à construção que representa o maior lucro. Se construirmos apenas no próximo período, e ocorrer o cenário favorável, o preço de mercado de cada apartamento será de 120 u.m., construiremos nove apartamentos e teremos um lucro igual a 270 u.m. (9x120-810); se ocorrer o cenário desfavorável, o preço de mercado de cada apartamento será de 90 u.m., construiremos seis apartamentos, e teremos um 
lucro igual a 60 u.m. (6x90-480). Aplicando o modelo binomial a esta situação temos que:

$$
\begin{array}{lll}
u=1.2 & d=0.9 & r=12 \% \\
S=100 \text { u.m. } & f_{u}=270 \text { u.m. } & f_{d}=60 \text { u.m. } \\
S_{u}=120 \text { u.m. } & S_{d}=90 \text { u.m. } &
\end{array}
$$

Substituindo os valores na expressão (1) temos que,

$$
\Delta=\frac{f_{u}-f_{d}}{S(u-d)}=\frac{270-60}{100(1.2-0.9)}=7
$$

Substituindo este valor na expressão (2) vem que,

$$
f=S \Delta-\left(S_{u} \Delta-f_{u} \frac{1}{(1+r)^{T}}=100 \times 7-(120 \times 7-270) \times \frac{1}{(1+.12)}=191.07\right.
$$

Portanto o valor do terreno determinado através do modelo binomial será igual a 191.07 u.m.

Fica demonstrado que a incerteza associada ao tipo de construção óptima é extremamente importante na avaliação de um terreno: quanto maior a incerteza relativamente à melhor construção a realizar no futuro, maior o valor da opção futura e maior o valor do terreno, tornando menos atractiva a tomada da decisão hoje. Por outro lado, se houver pouca incerteza relativamente ao tipo de construção a realizar no futuro, menor o incentivo em prorrogar a decisão de construção no futuro. Esta constatação tem algumas implicações ao nível dos efeitos de algumas políticas de habitação. Por exemplo, as restrições do número de andares poderão resultar num incremento do nível de construção, devido à diminuição da incerteza relativamente à altura óptima dos edifícios a construir no futuro; uma legislação de habitação dúbia aumenta a incerteza, quanto ao tipo de construção passível de ser realizada, diminuindo, hoje, o nível de construção.

\section{CONCLUSÃO}

A selecção do(s) método(s) a aplicar depende tanto dos objectivos da avaliação imobiliária como da disponibilidade e qualidade dos dados de mercado. Numa situação irreal, de mercado perfeito, obter-se-ia sempre, independentemente da metodologia aplicada, o mesmo valor para um dado imóvel.

Na perspectiva financeira, a metodologia dos cash-flows descontados apresenta-se como a solução mais correcta para a problemática da avaliação de acti- 
vos imobiliários. Isto apesar das dificuldades levantadas na determinação do custo do capital próprio nos investimentos imobiliários.

Na prática deverá utilizar-se, sempre, pelo menos dois métodos de avaliação imobiliária, por forma a possibilitar a comparação e confirmação dos valores obtidos.

\section{NOTAS}

1 Activos Reais, onde incluímos os imóveis, passíveis de serem vistos, sentidos e tocados.

${ }^{2}$ Activos Financeiros, tais como obrigações e as acções, representativos de direitos sobre Activos Reais.

${ }^{3}$ Segundo Brealey e Myers (1992:290), um mercado diz-se perfeito quando são satisfeitas as seguintes condições: (i) não há qualquer tipo de barreiras que dificultem o acesso ao mercado e que nenhum dos participantes é suficientemente poderoso para exercer um efeito significativo sobre o preço; (ii) o acesso ao mercado não implica custos e não há quaisquer "resistências" que impeçam a livre transacção dos imóveis; (iii) a informação relevante acerca do preço e qualidade de cada activo é ampla e livremente disponível; (iv) não existem impostos.

${ }^{4} \mathrm{O}$ rendimento bruto potencial corresponde ao valor das rendas obtido para a situação em que todo o espaço está ocupado. O rendimento bruto efectivo será igual ao rendimento bruto potencial menos o valor das rendas do espaço não ocupado.

${ }^{5} \mathrm{O}$ resultado operacional é calculado subtraindo ao rendimento bruto efectivo os custos operacionais.

${ }^{6}$ Posição longa: corresponde à moeda, activo ou instrumento financeiro detidos pelo investidor, indicando uma posição liquida positiva.

${ }^{7}$ Posição curta: corresponde à venda de moeda, activo ou instrumento financeiro que o investidor não detém, indicando uma posição liquida negativa ou déficit.

\section{APÊNDICE}

\section{Índices imobiliários:}

FRC (Frank Russell Company): Série trimestral constituída por aproximadamente 1000 propriedades detidas por fundos de investimentos imobiliário. O valor médio de cada propriedade é cerca de 10 milhões de dólares. Esta série existe desde 1978. 
REIT ( $G s$ \& Co. Equity) Série mensal composta pelas propriedades de trinta e três fundos de investimentos imobiliário em iguais proporções, existente desde 1974. Estes índices, comparativamente com os FRC, estão mais concentrados em Shopping centers e apartamentos e menos em escritórios.

EAFPI (Evaluation Associates) Série trimestral construída com base nos retornos de trinta e três fundos de investimento imobiliário. Esta série existe desde 1969.

\section{BIBLIOGRAFIA}

ALVAREZ, J., Vieira, E. (1994), Vocabulário Urbanístico, 2. ed., Lisboa, Direcção Geral do Ordenamento do Território e Desenvolvimento Urbano.

BRIGHAM, E., GAPENSKI, L. (1996), Intermediate Financial Management, 5.th ed, New York, Dryden Press.

BRUEGGEMAN, W., B., FISHER, J., D., STONE, L., D., (1989) Real Estate Finance, 8th ed., Boston, Richard D. Irwin, Inc.

CAMPOS, D. L., (1990), Direito das Empresas, Lisboa, Instituto Nacional de Administração.

CARVALHO, J., M. (1997), Avaliação de activos imobiliários, Lisboa, Trabalho apresentado na Cadeira de Gestão de Risco do MBA da Universidade Católica Portuguesa, Lisboa (mimeog.).

COPELAND, T., KOLLER, T., MURRIN, J. (1996), Valuation - Measuring and Managing the Value of Companies, 2nd. ed., New York, John Witey \& Sons, Inc.

DAMODARAN, A. (1996), Investment Valuation - Tools and Techniques for Determining the Value of Any Asset, New York, John Wiley \& Sons, Inc.

FIGUEIREDO, R. M. (1991), Sistema de Informação Imobiliária e de Apoio a Avaliação, Lisboa, Instituto Superior Técnico.

FIGUEIREDO, R., BEZELGA, A., A., (1996), Metodologias de Avaliação Imobiliária Corrente, Lisboa, Associação Portuguesa de Avaliações de Engenharia.

FIGUEIREDO, R., M. (1996), Medição de Desempenho do Investimento no Imobiliário, Lisboa, Associação Portuguesa de avaliações de Engenharia.

FITCH, T., P. (1993), Dictionary of Banking Terms, 2nd, ed., New York, Barron's Educational Series, Inc.

HULL, C., J. (1997), Options, Futures and Other Derivatives, $3^{\text {rd }}$ ed., New York, Prentice Hall. LOFTHOUSE, S. (1994), Readings in Investments - Real State, New York, John Wiley \& Sons.

MARQUES, M., O. (1996), O Valor da Empresa, Lisboa, Programa de MBA com Especialização em Finanças da Universidade Católica Portuguesa. 
RODRIGUES, P., E. (1995), Metodologia de Avaliação para Financiamento de Empreendimentos Imobiliários Considerando Factores de Risco e Qualidade, Porto, Universidade do Porto - Faculdade de Engenharia.

TAVARES, C. (1996), A Avaliação do Imobiliário na Óptica da Banca e do Mercado, Lisboa, Associação Portuguesa de Avaliaçðes de Engenharia.

TAVARES, L., V. (1996), O Valor do Imobiliário, Lisboa, Associação Portuguesa de Avaliações de Engenharia.

TAVARES, L., V. (1997), Gestão de Investimentos Imobiliários, Lisboa, Curso de Especialização em Gestão de Investimentos Imobiliários, Instituto Superior Técnico, Departamento de Engenharia Civil.

TITMAN, S. (1985) «Urban Land Prices Under Uncertaintly», The American Economic Review, 505-514.

ZISLER, R., C.; FIRSTENBERG, P., M.; ROSS, S., A.; «Real Estate: The Whole Story», Journal of Portfolio Management, 14, Spring, 22-34. 